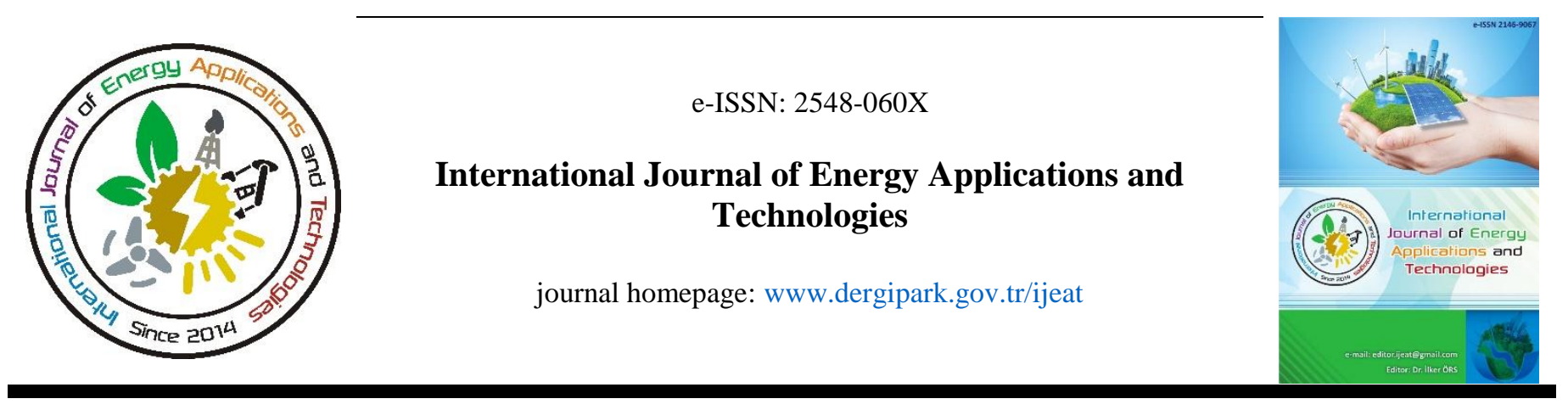

Original Research Article

\title{
Autonomous solar panel cleaning robot with rubber wheeled and air-absorbing motor
}

\author{
Burak Behlül Ölmez ${ }^{1}$, Özge Ergezer², Gül Nihal Güğül ${ }^{3 *}$ \\ ${ }^{I}$ Akın ROBOTICS Tatlicak, D330 No:116, 42030 Karatay/Konya, Türkiye \\ ${ }^{2}$ Selcuk University, Faculty of Technology, Department of Computer Engineering Graduated Student, Konya, Türkiye \\ ${ }^{3}$ Selcuk University, Faculty of Technology, Department of Computer Engineering, Konya, Türkiye
}

\author{
ARTICLE INFO \\ * Corresponding author \\ gul.gugul@selcuk.edu.tr \\ Received May 17, 2021 \\ Accepted October 27, 2021 \\ Published by Editorial Board \\ Members of IJEAT \\ (C) This article is distributed by \\ Turk Journal Park System under \\ the CC 4.0 terms and conditions.
}

doi: 10.31593/ijeat.938629

\begin{abstract}
De-dusting of photovoltaic panels enables the panels to produce the targeted power. In this study, an autonomous, water-free, self-energy source contained, air sucking robot which was not encountered in the literature research, was designed and developed. The developed robot can be adapted to each power plant by entering the photovoltaic panel path into the robot.

The developed robot can be controlled by a joy stick or autonomously. Robot supplies own energy demand by the flexible solar panel mounted on it. Robot does not have any cable or water pipe connection, allowing to work flexibly. Rubber wheels allow nonslip omnidirectional rotation. Main effectiveness of the robot is the air vacuum instead of an air spray. Air spray sends dust from one point to another while blowing, whereas in this study dust is sucked from the surface using an air vacuum. Vacuumed dust can be stored in the storage of robot or can be thrown away to ground by a hose. The only essential human interference of the developed robot is amending of micro fiber cloths and emptying the dust if stored. Another advantage of the developed robot is being cost effective.
\end{abstract}

\section{Introduction}

Photovoltaic panels generate their nominal power when the solar radiation is sufficient and the panel surface is clean. Power generation capacity of solar panels can be reduced up to $30 \%$ due to dust and dirt. Cleaning the panels with detergents and various chemical cleaners is time consuming, expensive, dangerous for the environment and can significantly damage the structure of the panels. Cleaning the panels of large scale solar power plants is troublesome especially in areas with water shortage. Power loss due to dusting depends on the type of dust, the frequency of rain and the cleaning schedule [1].

There are three methods used to clean photovoltaic panels: Manual cleaning, electrostatic cleaning and mechanical cleaning. Manual cleaning is a common method used with the purpose of removing dust and dirt from photovoltaic panels. In this cleaning method, users decide the cleaning schedule of panels and generally cleaning is done at least once a month using pure water [1]. Disadvantage of manual cleaning systems is the determination of cleaning time and periods by the staff whereas inaccurate time determination causes to reduce the electricity produced. Also, this method has an extra cost for the staff. Another method of solar panel cleaning is electrostatic cleaning which consists of a sandrepellent layer of parallel electrodes embedded under solar panel glass. Dust particles are removed from the panel surface by creating a flip-flop movement in the device. There are studies conducted to improve electrostatic cleaning whereas still in laboratory conditions ([2-5].).

Most preferred method for cleaning of PV is mechanical cleaning of which generally executed by water, brushes or 
air. A dry cleaning method was developed in a study conducted in the Middle East region, which is a very suitable region in terms of solar energy potential but has too much sand/dust problems and water scarcity. Dry cleaning was done with compressed air spray. A foam roller and a polywool synthetic eraser remove the dust from the surface. Components are fixed on a triangular plate. The triangle assembly is rotated $60^{\circ}$ by a stepper motor at the end of each cleaning step [6]. Another dry implementation of a PV cleaning robot with an object-oriented sensor design was developed to remove dust from PVs in United Arab Emirates. Robot consists of a cleaning brush driven by a motor and travels above and below each panel to move vertically along the entire array. The robot is expandable to easily adapt to different sized systems [7]. In a study conducted in Turkey, a microcontroller-based solar panel cleaning robot that includes a horizontally moving double motor and a crawler robot is designed and developed. Aluminum sigma profiles already existing in photovoltaic panels are used as a frame and the rail system provides the device with the advantage of lightness [8]. Another dry PV panel cleaning robot with air spray feature was designed and developed which was energy independent, self-automated, long durable, and costeffective. Moreover, the image processing with the photos taken by a camera fixed on the robot made classification according to color changes in the solar panel [9]. A research conducted in Thailand aimed to design and develop a PV panel cleaning robot which works suitable in Thailand weather conditions, is used with joystick, controlled with Arduino, and cleans with a rotary brush and water [10]. An unmanned, low-cost and dry robot operating without rails or guides is implemented in a study in Italy. The robot senses its position with ultrasonic sensors and regulates its speed and direction of movement. Arduino based control system settles the robot travel direction, its speed and the brush that must be activated [11]. A robot is developed in another study of which's primary element was android control switch unit, IP camera, sensors of voltage and current. The obtained data is send to the processor that is integrated by using the Arduino IDE. Robot has DC motor for movement control, media server for sending video from the IP camera to the android apps, and bluetooth module integrated with android apps to test the level of voltage and current [12].

Besides academic studies, there are some robots developed in the commercial sector. GEKKO Solar [13] developed a robot that cleans PV by brushes, applying constant pressure to the panels and using demineralized water. The operator can comfortably lift and control the robot by using a joystick. SunBrush PV cleaning system with mobile cleaning brush is suitable for desert areas as well as for wet cleaning using demineralized water [14]. Heliotex robot does not require any maintenance other than occasional refilling of the soap and changing the water filters [15]. HECTOR-HEliostats Robot is wireless, rechargeable and carrying water solution tank. The robot is autonomous and does not require external power or water supply to operate; carries its own battery and water tank [16].

Automatic cleaning systems with electrostatic surface technology are effective because they are constantly active and have low power consumption. Mechanical automatic cleaning systems are divided into wet and dry systems. While the biggest problem in desert regions is dust, scarce of water is another major problem. For this reason, dry systems attract more attention. The main aim of PV cleaning systems is to develop a low cost, low power consumption and high cleaning efficiency system. Electrostatic cleaning is the method that involves all these goals. However, many studies are still carried out in the laboratory environment. Dryautonomous cleaning robots also seem attractive as they are staff and water free. Another problem of PV cleaning robots is power consumed. Automated cleaning robots with a renewable resource can be more efficient and more mobile.

For this reason, an autonomous, water-free, self-energy source contained, air sucking robot which was not encountered in the literature research, was designed and developed in this study. The developed robot can be adapted to each power plant by entering the photovoltaic panel path into the robot. Developed robot can be selectively controlled both by a joystick or autonomously.

\section{Material and Methods}

Main problems encountered in the cleaning of photovoltaic panels are the requirement of human control, excessive water consumption, inefficient collection of dust, cable and hose connections all of which have been eliminated with the developed robot. The only required external intervention of the developed robot is change of micro fiber cloths and emptying the dust if stored whereas instead of storing, dust can be discharged directly to the ground with the help of a hose. At the same time, the robot has the ability to work without any human control. Another advantage of the developed robot is being cost effective.

The steps followed in the development stage of the robot are explained in this section under two titles as hardware and software. The flow chart of the robot is given in Figure 1.

\subsection{Robot hardware}

Four 3D Printing Mecanum Rubber Robot Wheels are used in the robot, providing movement in any direction and strengthening its maneuverability by preventing the robot from slipping on the inclined panels due to its strong grip on the area where it is located. There are four 24 volt $1500 \mathrm{Rpm}$ Gearmotors that give the movement capability to four wheels and the control will be provided by the motor driver card 
connected to the Arduino [17]. There is a $0.37 \mathrm{~kW} 2000 \mathrm{~m}^{3}$ winged snail aspirator that sucks air from the box placed on the brushes. Robot can determine the direction to go autonomously according to user directions or the path inside. Path of the robot is entered to the software by the user according to the arrangements given below;

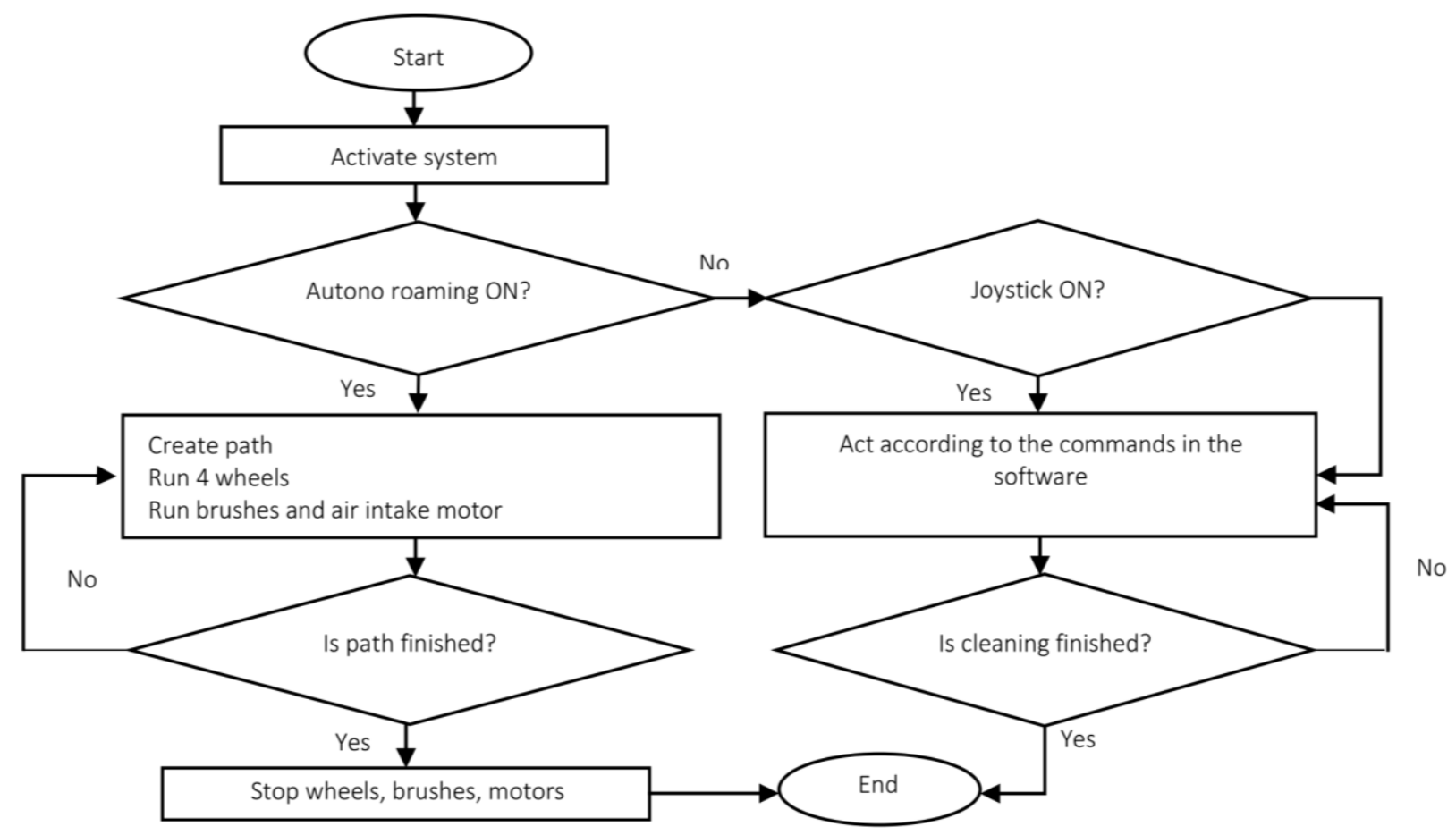

Fig. 1. Flow chart of the working principle of the robot

- Panel arrangement, width and height information of the solar power plant will be obtained.

- The route that the robot will follow will be created according to the information obtained.

- The robot will proceed straight from the place determined as the starting point to the end of the panels.

- Since the speed of the robot and the width of the panels are known and constant, the robot will know the duration to go forward.

- At the end of the panels, the mechanism will move up and down as much as a brush length thanks to the wheels and one line will be cleaned.

- At the next row, the robot will move straight against the direction it came from, as much as the calculated time along that row.

- This process will repeat until all the area cleaned.

- Robot will know the end point from the route we have determined and terminate the process.

- When the cleaning process is over, the robot will give a sound warning.

Panels are cleaned with Xiomi Smart Vacuum Cleaner Filter Set. These filters can be changed as they get dirty. With the Sunpower Lexron 130 W 12V Monocrystalline Flexible Solar Panel placed at the top of the robot, robot provides its own energy from the sun and does not require any extra power source and there is no cable connection that restricts movement. The energy produced by the flexible panel is stored in two 12 Volt 7A batteries.

\subsection{Robot software}

The autonomous robot has double control option with the software loaded. Robot can move autonomously or can be controlled by joystick according to the selected mode which is performed with the switch on the robot. Robot can clean harmoniously photovoltaic plants of all sizes by the help of the software that allows to be adjusted according to the arrangement of the solar panels. In order to enter the path that the robot will follow, width and height of the solar power plant must be obtained. According to the information obtained, the route to be followed by the robot will be created and the robot will proceed straight from the place determined as the starting point until the end of the panels. Since the speed of the robot is constant and it knows the length of the road, robot calculates the duration of road in seconds. When it comes to the end of the panels, the mechanism moves up and down a brush length by means of the wheels and moves straight along that row, in opposite to the direction it came. It will repeat these processes until it reaches the end point. Knowing the end point from the size, the robot ends the process when all panels are cleaned.

Arduino was used to adjust the brush speed with the help of variable resistance in the cleaning process. In this way, if the 
cleaning process is done frequently, the speed of the brush can be set lower, if it is done at longer intervals, the speed of the brush can be set higher.

\section{Results and Discussion}

The robot in this study, has been designed and developed to clean the dust and dirt on photovoltaic panels. The robot differs from other robots in that it can move both manually and autonomously, work water-free, generate its own energy and intake the dusty air instead of blow. In this section hardware and software results of the robot are given.

\subsection{Robot hardware}

The circuit diagram of the developed robot is drawn by using Proteus software [18] and given in Figure 2, and the material list used is shown in Table 1.

Power analyses of the entire system is given in Table 2.

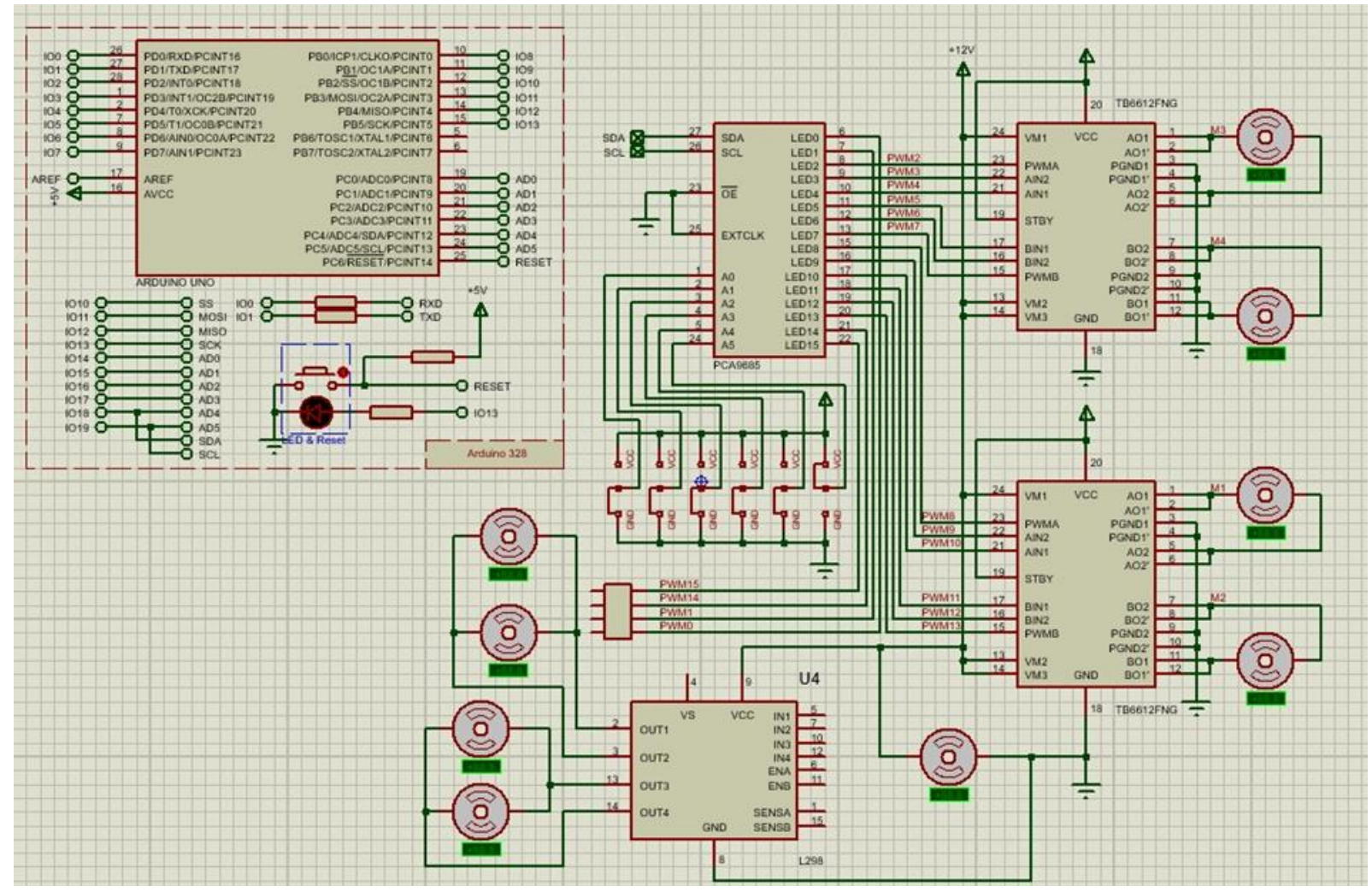

Fig. 2. Circuit diagram of the robot

Table 1. Cost, technical specifications and purposes of the materials used in the robot

\begin{tabular}{|c|c|c|}
\hline Robot Hardware & $\begin{array}{l}\text { Price, } \\
\text { USD }\end{array}$ & Technical feature and purpose \\
\hline 3D Mecanum Wheel 60mm * (4 pcs) & 49 & All-round mobility and adhesion to surface \\
\hline Arduino 4wd Car Chassis (wood) & 2 & Material fixing and sub-frame of the robot \\
\hline Robot Chassis 210x160mm & 10 & Robot fixing \\
\hline 24V 1500 Rpm Motor * (4 pcs) & 128 & Providing the movement of the wheels \\
\hline 24 V 1500 Rpm $2000 \mathrm{~m}^{3}$ Air Intake Motor & 26 & Intake the dusty air \\
\hline Arduino Mega 2560 R3 Klon & 10 & Performing basic input/output applications with other materials \\
\hline 5V 9MM H:5 circuit Buzzer & 1 & Used to give audible warning at the start/stop \\
\hline 50K 3590 Potential Multi-Rounds & 2 & $\begin{array}{l}\text { As you turn the pot its resistance changes. Used for sub-broom speed } \\
\text { adjustment }\end{array}$ \\
\hline HC06 Arduino Bluetooth Module & 3 & Responds to connection requests. It was used for remote control. \\
\hline Vr-Box Bluetooth remote control & 3 & Remote control \\
\hline 12 Volt 7A Battery & 7 & Storing the power from the panel \\
\hline Flexible PV Panel, 130 W Monocrystalline & 198 & Electricity production \\
\hline Smart Vacuum Cleaner Filter Set & 28 & Provides cleaning with curved brushes \\
\hline TOTAL & 465 & \\
\hline
\end{tabular}


Table 2. Power analyses of the entire system

\begin{tabular}{|c|c|c|c|c|c|}
\hline & Robot Hardware & Current, Ampere & Voltage, Volt & Pes & Power, W \\
\hline \multirow{5}{*}{$\begin{array}{l}\text { Electricity } \\
\text { Consumed }\end{array}$} & 24V 1500 Rpm Motor & 0.64 & 24 & 4 & 15 \\
\hline & 24 V 202 Rpm Air Intake Motor & 4.1 & 24 & 1 & 100 \\
\hline & Arduino Mega 2560 R3 Klon & 0.05 & $7-12$ & 1 & 0.5 \\
\hline & 5V 9MM H:5 circuit Buzzer & 0.025 & 5 & 1 & 1.25 \\
\hline & Cleaning motor & 0.095 & 6 & 3 & 1.71 \\
\hline Electricity & 12 Volt 7A Battery & 7 & 12 & 2 & 168 \\
\hline Produced & Flexible PV Panel, $130 \mathrm{~W}$ Monocrystalline & 7 & 18 & 1 & 130 \\
\hline
\end{tabular}

As seen in Table 2, power demand of the robot can be supplied by the photovoltaic system. The photo of the developed robot is given in Figure 3.

As seen in Figure 3, the robot takes its energy from the blown panel placed on it. The reason for using flexible panels in this study is that it is much lighter and flexible that gives the

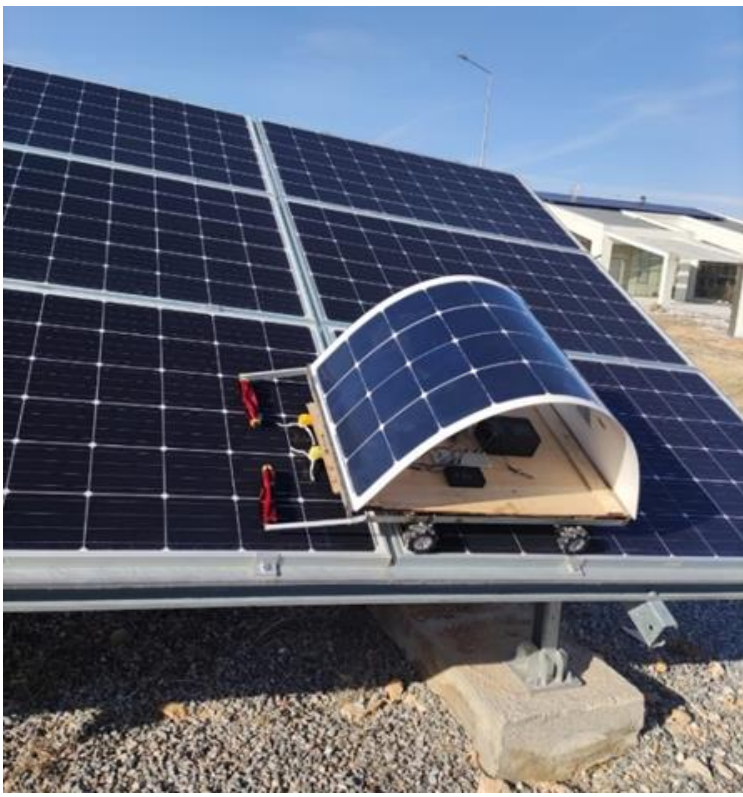

Fig. 3. Photo of the developed robot opportunity to use a panel with greater power than we would normally use. The robot, which receives its energy from the panel, transmits the energy to the motors and moves in line with its software. In autonomous mode, robot does not clean the same place twice.

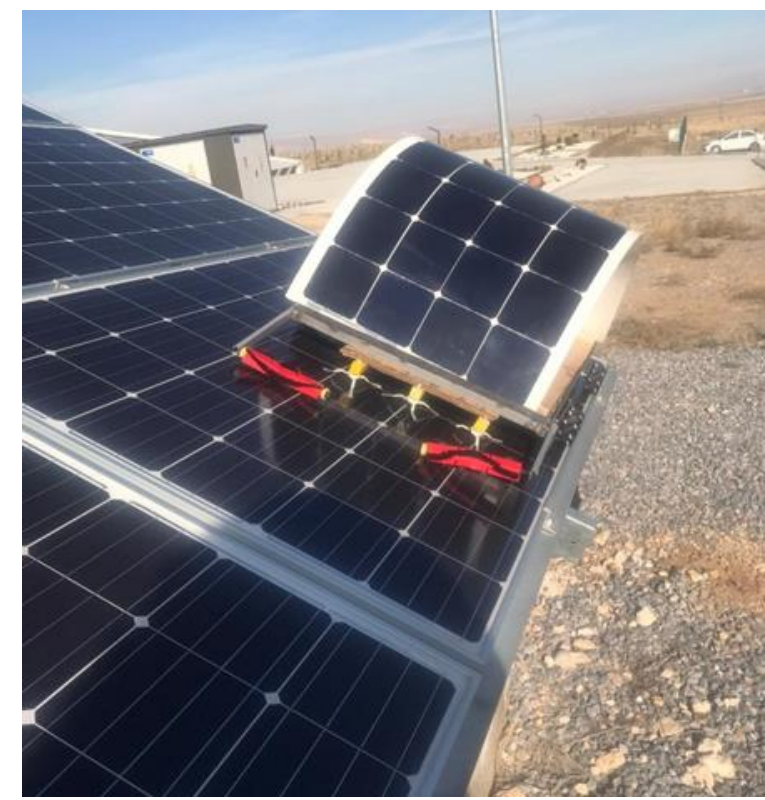

\subsection{Robot software}

In the first stage of software, duration of path is calculated according to rotational speed and the angle of rotation. Then, pin inputs of 4 motors and enabled and set constant. Motor movements with the stop command has set when the duration of movement has ended. After that, the setup part, that is run once after the Arduino starts working or after pressing the reset button. Functions are executed once. Loop initiation function is infinite loop functions. It is executed right after the setup () function and continues as long as the arduino is running. A path is created according to the arrangement of the panels in solar power plant and optional coding is made according to this path. The robot, left in the top row, works autonomously until it reaches the last part, by cleaning the panels sequentially, without returning to the part it cleans. Also there are codes written for manual control instead of autonomous control. In addition to this by the help of application developed speed of the robot can be adjusted.

\section{Conclusion}

Regular cleaning of photovoltaic panels is very important for producing the targeted energy. Many methods have been developed and continue to be developed for cleaning of the panels. The main problems of existing robots are that some of them work with water, some require energy, some have to work with human control, and some robots use detergent 
materials. For this reason, in this study, a robot that can act autonomously, water-free, produces its own energy, intakes dusty air instead of blowing and differs from other robots by having all these features together has been developed in order to clean photovoltaic panels in a cost effective way. The developed robot does not need human control other than changing the micro fiber glands at regular intervals.

\section{Acknowledgment}

This project was supported by Selcuk University Scientific Research Projects (Grant Number:20402008).

\section{$\underline{\text { ORCID }}$}

B. B. Ölmez

Ö. Ergezer

G. N. Güğül

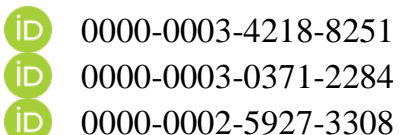

\section{References}

[1] Boztepe, M., 2017. Fotovoltaik Güç Sistemlerinde Verimliliği Etkileyen Parametreler. İzmir

[2] Kawamoto, H., 2019. Electrostatic cleaning equipment for dust removal from soiled solar panels. Journal of Electrostatics, 98, 11-16.

[3] Sayyah, A., Horenstein, M. N., Mazumder, M. K., 2015. Performance restoration of dusty photovoltaic modules using electrodynamic screen. New Orleans, 13.

[4] Mazumder, M., Sharma, R., Biris, A., Horenstein, M., Zhang, J., Ishihara, H., Stark, J., Blumenthal, S., Sadder, O., 2011. Electrostatic Removal of Particles and its Applications to Self-Cleaning Solar Panels and Solar Concentrators. Developments in Surface Contamination and Cleaning. William Andrew ASP, 149-199.

[5] Fathi, M., Abderrezek, M., Friedrich, M., 2017. Reducing dust effects on photovoltaic panels by hydrophobic coating. Clean Technologies and Environmental Policy, 19, 577-585.

[6] Aly, S. P., Gandhidasan, P., Barth, N., Ahzi, S., 2015. Novel dry cleaning machine for photovoltaic and solar panels. Marrakech, 1-6.

[7] Baloushi, A. A., Saeed, M., Marwan, S., AlGghafri, S., Moumouni, Y., 2018. Portable robot for cleaning photovoltaic system: Ensuring consistent and optimal year-round photovoltaic panel performance. Abu Dhabi, 1-4.

[8] Akyazi, O., Sahin, E., Ozsoy, T., Algul, M., 2019. A Solar Panel Cleaning Robot Design and Application. European Journal of Science and Technology, 343-348.
[9] Park, H., Öztürk, A., Park, H., Khan, M. U., 2019. Utilization of Robotics for Solar Panel Cleaning and Maintenance. Konya Journal of Engineering Sciences, 7(4), 768-775.

[10] Ronnaronglit, N., Maneerat, N., 2019. A Cleaning Robot for Solar Panels. Luang Prabang, Laos, 1-4.

[11] Antonelli, M. G., Zobel, P. B., Marcellis, A. D., Palange, E., 2020. Autonomous robot for cleaning photovoltaic panels in desert zones. Mechatronics, 68.

[12] Hashim, N., Mohammed, M. N., Selvarajan, R. A., AlZubaidi, S., Mohammed, S., 2019. Study on Solar Panel Cleaning Robot. Selangor, Malaysia, 56-61.

[13] Serbot, 2020. Gekko Solar. https://www.serbot.ch/en/solar-panels-cleaning/gekkosolar-robot (30 December 2020)

[14] SunBrush, 2020. SunBrush Mobil. https://sunbrushmobil.info/the-mobilsunbrush/?lang=en (21 December 2020)

[15] Heliotex, 2020. Solar Panel Cleaning Services. https://www.solarpanelcleaningsystems.com/solarpanel-cleaning-services.html (14 December 2020)

[16] Sener, 2020. HECTOR-HEliostats Cleaning Team Oriented Robot. http://www.seneraerospace.com/EPORTAL_DOCS/GENERAL/SENE $\underline{\text { RV2/DOC-cw509b9c7d13fbf/hector-heliostats- }}$ cleaning-team-oriented-robot.pdf (01 February 2020)

[17] İkizoğlu, K., 2020. Projelerle Arduino. Dikeyeksen.

[18] Proteus, 2020. https://www.labcenter.com/downloads/ (22 March 2020) 